\title{
LEGIA L'ENEYDOS E MOLTS ALTRES LIBRES. DOCTAE PUELLAE EN EL CURIAL E GÜELFA
}

\author{
Sonia Gros Lladós. \\ UNED. Girona \\ sgroslla@gmail.com
}

\section{RESUMEN}

El objetivo de este trabajo es analizar algunos paralelos de las damas de la novela caballeresca catalana Curial e Güelfa con rasgos representativos de los modelos femeninos dominantes en la tradición erótica de los clásicos grecolatinos, en especial, el de la docta puella de los poetas elegíacos.

Palabras Clave: Curial e Güelfa, Docta puella, Tradición clásica.

\section{Abstract}

This paper aims to analyze some parallels between ladies in Catalan chivalric novel Curial e Güelfa and female models dominating in erotic classical tradition, especially about docta puella elegiac motif.

KeY wORDs: Curial e Güelfa, Docta puella, Classical Tradition.

Los estudios más recientes sobre la novela caballeresca catalana Curial e Güelfa subrayan de manera unánime la variedad y riqueza de la cultura literaria de su anónimo autor $^{1}$, quien recoge y fusiona en su obra de manera armónica diversas tradiciones - de

\footnotetext{
${ }^{1}$ Entre los más destacados Butinyà, Júlia (2001): Tras los orígenes del Humanismo: el «Curial e
} 
las fuentes cristianas a la literatura trovadoresca y caballeresca y las Crónicas catalanasy el papel crucial en la novela de los clásicos grecolatinos como Ovidio y Virgilio, y de los trecentistas italianos -Dante, Petrarca y Boccaccio- como intermediarios de la tradición clásica. En este sentido nos proponemos señalar algunos paralelos de las damas de la novela catalana con rasgos representativos de los modelos femeninos dominantes en la tradición erótica de los clásicos, y más concretamente del modelo elegíaco latino que culmina en la poesía de Ovidio. Patrones elegíacos que resurgen con fuerza en el final del Medievo favorecidos por el redescubrimiento de los textos eróticos clásicos, principalmente de Catulo y Propercio, junto al omnipresente Ovidio, y el auge de la narrativa sentimental fuera y dentro de la Península. El objetivo de este trabajo es, pues, analizar algunos rasgos de las tres damas protagonistas de la novela desde la perspectiva del nuevo modelo femenino que se vislumbra en el atento diseño que el Anónimo nos ofrece de las damas en esta obra, y sugerir, por una parte, su relación con los modelos literarios utilizados por el autor, por otra, resaltar su valor como signo de un cambio incipiente de mentalidad, no solo en cuanto a la concepción femenina dominante en la obra, sino asimismo, del proceso más amplio de transformación literaria y cultural que se opera en el período en que se escribe la novela.

Tres mujeres completan el itinerario sentimental de Curial, el protagonista de la novela caballeresca catalana Curial e Güelfa. Güelfa, su protectora, presente desde el inicio hasta el final feliz de su relación, que culminará en el matrimonio. Làquesis y Càmar, en cambio, corresponden a dos etapas diferentes de su peregrinación vital. Las tres presentan numerosos rasgos en común. En primer lugar, los nombres que identifican a las tres jóvenes contribuyen de modo inequívoco a la caracterización de los respectivos personajes. Los nombres -siempre pseudónimos, ficta nomina- de las mujeres amadas en la elegía latina, como sucederá más tarde con Laura o Fiammetta, muestran una evidente intencionalidad literaria. Catulo evoca en Lesbia el refinamiento y la cultura de su amada al tiempo que rinde un homenaje a su admirada Safo. El nombre de la amada de Propercio, Cynthia, remite a Apolo, nacido en el monte Cinto en la isla de Delos, al igual que sucede con la Delia de Tibulo. Némesis alude a la diosa de la venganza y la crueldad de la amada. En el caso de la novela catalana, el nombre de su protagonista, Güelfa, refuerza la hipótesis de quienes defienden una intención política en la obra, que apoyaría los intereses del Magnánimo en el conflicto sucesorio del reino de Nápoles ${ }^{2}$. Respecto a Làquesis, el propio Melchior de Pandó interpreta, en una de sus admoniciones a Curial,

Güelfa», Madrid, UNED; Ferrando, Antoni (2007): Intr. y ed. Curial e Güelfa, Toulouse, Anacharsis; BAdiA, Lola \& Torró, Jaume (2010): «Curial entre Tristán y Orlando», Estudios sobre la Edad Media, el Renacimiento y la temprana modernidad, SEmYr, San Millán, pp. 43-60.; BADIA, Lola \& Torró, Jaume (2011): Intr. y ed. Curial e Güelfa, Barcelona, Quaderns Crema.

${ }^{2}$ «Si a això afegim que el tractament de la figura de Pere el Gran al Curial es fa amb un alt grau de versemblança, que el nom de la protagonista principal correspon al d'una de les faccions de la política italiana medieval i que al segle XV es reprodueix el conflicte entre els interessos angevinopontificis i els catalanoaragonesos a Itàlia quasi en els mateixos termes que al segle XIII, hi ha motius més que suficients per a considerar la hipòtesi d'una intencionalitat política en la nostra novel-la». Cf. FerRando, Antoni (1997): «Sobre el marc històric de Curial e Güelfa i la possible intencionalitat de la novel-la», Actes del Col-loqui internacional Tirant lo Blanc «L'albor de la novel-la moderna europea. Estudis crítics sobre Tirant lo Blanc i el seu context, Barcelona, PAM, p. 355. Espadaler, por su parte, defiende la opinión contraria: la novela, dedicada a la reina Maria, esconde, a su juicio, una crítica al abandono de Cataluña por parte del rey Alfonso. Cf. EsPadaler, Anton (1984): Una reina per a Curial, Barcelona, Quaderns Crema. 
según su sabio criterio, el sentido de su nombre, en relación a una de las Parcas (I, 85). El nombre, en nuestra opinión, presenta una fácil asociación con los laquei elegíacos, los lazos del amor, elementos que en la novela se repiten obsesivamente como símbolo de la seducción de la joven ${ }^{3}$. El nombre de Càmar, «luna» como indicó el doctor Riquer, por su parte, contribuye a la caracterización del personaje ${ }^{4}$, que lo cristianiza por decisión propia antes de morir en Johana.

De acuerdo con la tradición de la literatura sentimental desde antiguo, la amada es bella ${ }^{5}$. Pero, en este caso, llama poderosamente la atención el hecho de que la belleza de la amada está a la altura de la del héroe, tan hermoso o más que las damas. Este es uno de los motivos de la novela catalana que remite con mayor claridad a una nueva visión del mundo clásico. En la poesía griega destaca sobremanera entre las cualidades del amado o amada la belleza. La propia diosa del amor lo es también de la belleza. El motivo traspasa toda la literatura griega, desde Homero a la poesía helenística. Paris resplandece de belleza. Afrodita se enamora de Ares porque es bello. Para Safo lo más bello en la oscura tierra es «lo que uno ama»; y es la visión de la belleza lo que despierta el enamoramiento $^{6}$. La extrema belleza de los protagonistas, tanto masculinos como femeninos, era también uno de los elementos característicos de la novela sentimental griega, con un papel a menudo crucial en el desarrollo de la trama, reveladora del origen y carácter noble de los amantes ${ }^{7}$.

La belleza extraordinaria de Curial, en especial la de sus ojos deslumbrantes, constituye, en efecto, uno de sus rasgos distintivos puesto de relieve una y otra vez por el narrador y por diversos personajes, además de un motivo esencial en la trama de la obra:

Lo marquès se aturà e mirà'l, e, bé que fos en tendra edat constituït, no menys li viu los ulls molt resplandents e tanta bellesa en la sua cara que natura més no $\cdot n$ podia donar; per què respòs tantost:

${ }^{3}$ Gros, Sònia (2012): «Omnia uincit Amor: la força de l'amor en el Curial e Güelfa», eHumanista/IVITRA, 1, pp. 197-239. La asociación no parece en absoluto descabellada: el término laqueus es habitual en los elegíacos en este sentido. Contaba, pues, con una larga tradición literaria que recoge entre otros Petrarca, quien confiesa con esta imagen en el Secretum su amor ardiente por Laura: «Incautus in laqueum offendi» (III, 27). Para la asociación de Làquesis con el lazo del demonio y la muerte espiritual, cf. HAUF, Albert G. (2004): «Làquesis: la personificación de la seducción en el Curial e Güelfa», Letteratura cavalleresca tra Italia e Spag$n a(d a$ «Orlando» al «Quijote»). Literatura caballeresca entre España e Italia (del «Orlando» al «Quijote»), ed. Folke Gernert. Salamanca, Seminario de Estudios Medievales y Renacentistas, pp. 261-284.

${ }^{4}$ Recientemente Butinyà lo analiza bajo el influjo de Dante, cf. BUTINYÀ, Júlia (2011): «Dues dones del Curial (Càmar, la Güelfa) i els seus models», Congrés Internacional Any Isabel de Villena. Dones i literatura entre l'edat mitjana i el renaixement, València, IAM (en prensa). En cualquier caso, tampoco es descartable en un personaje con la trayectoria de Càmar y en el contexto de un episodio de influencia virgiliana como el de la cautividad de Curial en el Norte de África, el recuerdo de la asociación de la luna a divinidades clásicas como Ártemis-Diana, diosa protectora de la virginidad.

5 Se ha subrayado el dato respecto a las heroínas del roman medieval y su relación con el amor cortés. Cf. SIMÓ, Meritxell (2000): «Les yeux et le coeur: beauté extérieure et beauté intérieure dans Curial e Güelfa», Le beau et le laid au Moyen Âge, Aix-en Provence, CUERMA, Université de Provence, p. 477. La belleza, no solo femenina, también masculina, en la novela catalana desempeña un papel clave, pero creemos que el tratamiento que ofrece el Anónimo presenta conexiones más evidentes con la tradición clásica, tanto en la poesía elegíaca como en la novela sentimental.

${ }^{6}$ Cf. Rodríguez Adrados, Francisco (1995): Sociedad, amor y poesía en la Grecia Antigua, Madrid, Alianza, pp. 44-46.

7 Cf. García GuaL, Carlos (1991): Los orígenes de la novela, Madrid, Istmo. 
- E a mi plau que meu sies.

E, regirant-se als seus, dix:

- Per ma fe, anch no viu tan gentil creatura ne que tant me plagués. (I, 44)

Curial cresqué en dies e en seny e en bellesa de la persona, en tanta singularitat que en comun proverbi de la cort era caygut que, quant alguna grandíssima bellesa nomenar volien, nomenaven la de Curial. E axí mateix com nostre senyor Déu li havia donada corporal bellesa, $a b$ aquella ensems li donà gràcia de quants hulls lo veyen; axí que no $\cdot 1$ veya persona que d'ell no s'enamoràs. (I, 44)

La belleza de Curial será, en efecto, la causa directa de su promoción social por parte del marqués, de la admiración general y del enamoramiento, primero de Güelfa, más tarde de Làquesis y Càmar. La belleza, no lo olvidemos, unida a su formación intelectual. Ambos rasgos constituyen una novedad en la concepción de héroe que presenta la novela. Si es notable la preocupación del autor por la dimensión cultural del protagonista, es, asimismo, necesario recordar que «al llarg de tota la novel-la hi ha una utilització meditada de la bellesa de l'heroi» ${ }^{9}$.Subrayamos, por nuestra parte, el dato sumamente significativo de que en el caso de Curial, además, la belleza no es un signo de su origen noble, sino un reflejo de sus virtudes intelectuales y morales, en perfecta coherencia con el propósito ejemplar de la novela. En opinión de Sabaté, «hi ha una reivindicació d'un nou tipus d'home ${ }^{10}$. En nuestra opinión, ese nuevo tipo de hombre, como iremos viendo en numerosos detalles, supone en realidad una aproximación a un modelo de héroe más cercano a los clásicos.

Las tres heroínas femeninas de la novela están, en este aspecto, a la altura de Curial. Son extraordinariamente bellas, aunque el autor no nos ofrece prácticamente ningún rasgo concreto de su belleza ${ }^{11}$. Los poetas latinos, por su parte, se muestran también parcos en la descripción física de sus amadas. Todos resaltan su belleza y su encanto sin aportar demasiados datos concretos. Catulo nos ofrece pocos detalles de Lesbia:

Salue, nec minimo puella naso

nec bello pede nec nigris ocellis

nec longis digitis nec ore sicco

nec sane nimis elegante lingua, $(\ldots)$

ten prouincia narrat esse bellam?

${ }^{8}$ Utilizamos la edición filológica del Curial e Güelfa: Ferrando, Antoni (2007), Intr. i ed. Curial e Güel$f a$, Toulouse, Anacharsis. Citamos indicando el libro y la página correspondiente.

9 SABaté, Glòria (2000): «La concepció de l'heroi al Curial e Güelfa», Zeitschrift für Katalanistik 13, p.10. La misma estudiosa afirma que «per a l'home medieval la bellesa és llum, tranquilitza i és signe de noblesa» (op. cit. p. 11) y observa que el cambio de mentalidad que se produce hacia el final de la Edad Media supone una nueva valoración de esta cualidad.

${ }^{10}$ Op. Cit. Sabaté, 2000, p. 11.

11 Espadaler subraya este aspecto en relación a la protagonista, Güelfa, y utiliza el dato como apoyo a su hipótesis de que el personaje oculta la figura de la reina María (1984, pp. 132-136). SIMÓ (2000, p. 477), por su parte, vincula tanto la belleza extraordinaria de las heroínas como la falta de rasgos realistas o individuales en la descripción de su belleza, a la tradición del amor cortés. En cualquier caso, recordamos que la economía descriptiva es un rasgo que caracteriza al Curial, no solo en cuanto a los personajes femeninos, y que los rasgos que el Anónimo acentúa en el tratamiento de la belleza entroncan igualmente con la tradición grecolatina. 
tecum Lesbia nostra comparatur?

o saeclum insapiens et infacetum! (Carmina 43$)^{12}$

Lesbia formosa est, quae cum pulcherrima tota est, tum omnibus una omnis subripuit Veneres. (Carmina, 86, 5-6)

Tibulo omite la descripción de sus amadas y Ovidio destaca sus rasgos más sensuales. Algo más explícito se muestra Propercio:

fulua coma est longaeque manus, et maxima toto

corpore, et incedit uel Ioue digna soror. (Carmina, II, 2, 5-6)

Nec me tam facies, quamuis sit candida, cepit

(lilia non domina sint magis alba mea;

Ut Maeotica nix minio si certet Hibero, utque rosae puro lacte natant folia),

nec de more comae per leuia colla fluentes, non oculi, geminae, sidera nostra, faces. (Carmina, II, 3, 9-14)

Tampoco, como corresponde al espíritu de la novela catalana, observaremos, en la descripción de las protagonistas femeninas, la marcada sensualidad de los versos de Ovidio:

Ut stetit ante oculos posito uelamine nostros,

in toto nusquam corpore menda fuit:

quos umeros, quales uidi tetigique lacertos!

Forma papillarum quam fuit apta premi!

Quam castigato planus sub pectore uenter!

Quantum et quale latus! Quam iuuenale femur! (Amores, I, 6, 17-22)

Es bien sabido que en la descripción de la seductora Làquesis, el Anónimo remite a la descriptio puellae de la bella Helena de la Historia destructionis Troiae. De la detallada descripción de Guido delle Colonne, que ya se halla en Benoit de Saint-Maure, se subraya habitualmente que sigue las pautas medievales ${ }^{13}$. Sin embargo, si repasamos con atención los textos, no es difícil apreciar que la tradición remite en último término al canon de belleza femenina de los autores grecolatinos. Guido delle Colonne fija su atención en el cabello rubio como el oro, los ojos como estrellas, la blancura de rostro como leche, los labios seductores, los dientes de marfil, que representaban lirios mezclados con rosas, la piel nívea, las manos alargadas, la figura proporcionada, en definitiva, los mismos rasgos que Propercio destacaba en Cintia. Y alude, asimismo, como Ovidio, a los pechos de Helena.

En el combate de bellezas entre Festa y Làquesis, el narrador plasma los comentarios de quienes las contemplan admirados:

- A, santa Maria, quinys hulls!

Altres deyen:

- O, Déu, quina boca e dens! (II, 187)

${ }^{12}$ Los textos de los poetas elegíacos latinos corresponden a Catulli, Gai Valerii, Carmina, ed. Mynors R.A. B., 1960, Oxford, OUP; Ovidi Nasonis, P. Amores, Medicamina faciei feminae, Ars amatoria, Remedia amoris, ed Kenney, E.A., 1989, Oxford, OUP; Propertii, Sexti, Carmina, ed. Barber, E.A. 1987, Oxford, OUP.

${ }_{13}$ Marcos Casquero, M. A. (1996): Intr. y trad. Guido delle Colonne, Historia de la destrucción de Troya, Madrid, Akal, p. 150, n. 12. 
Y un poco más adelante, el narrador subraya los mismos rasgos físicos, a propósito de la belleza de Festa:

...ab tanta art, ab tant saber atquirit per lonch e treballós studi, mogué les mans, e ab aquells delicats, prims e lonchs dits, e ab aquelles ungles de vori, ajustà bellesa a belleses, car en la sua cara, cap, pits ne mans, no vagava cosa alguna que millorament de afaytar ne creximent de bellesa artificial reebre pogués. (II, 187)

En la presentación de Güelfa se nos revela de buen principio su belleza. El señor de Milán se enamora de la joven «oynt la fama de la bellesa de la Güelfa, la qual sens alguna comparació traspassava en aquell temps la bellesa de totes les donzelles de Ytàlia» (I, 45). No solamente se remarca su belleza a lo largo de la obra, sino que esta se extiende a su criada Festa, que compite con la propia Làquesis ante la admiración general:

Miraven-la tots e totes; la qual, com la vessen plena de incredible bellesa, tothom se li acostava volenterosament. Festejava-la la reyna en extrem; loava la sua bellesa, no solament perquè era gran e molta, mas encara per fer despit a Làquesis. Axí que les belleses d'aquelles dues se combatien contínuament, e no ·s podien vençre la una a l'altra. (II, 186)

De entre las damas, todas bellas, es quizás Làquesis la que sobresale, a juicio del narrador, por su belleza hiperbólica, de la que nos ofrece algún detalle -sus ojos, como Curial- un poco más concreto, aunque, como comentábamos, expresamente renuncia a explayarse en la descripción de sus encantos.

No vull musar en escriure per menut totes les circunstàncies de la sua bellesa, mas aquell qui ho voldrà saber lija Guido de Columpnis ${ }^{14}$ allà on descriu la bellesa de Elena ${ }^{15}$, e sie content ab allò; e pense que a Làquesis no li fallia bellesa, car certes natura, ab gran studi, per fer maravellar les gens la produí tal en lo món. E sobre totes les belleses que havia, sí tenia los pus bells hulls e pus resplandents e alegres que en algun temps fossen estats vists, ab los quals no era persona que ella miràs que de present no li fes oblidar totes les altres coses, e solament de mirar a ella haver cura contínua. (I, 79)

La belleza extrema de Làquesis, comparada, como sucedía en los versos de los elegíacos, con la de la mítica Helena, es resaltada una y otra vez por el narrador como motivo de la seducción de Curial, quien apunta su censura a través de las palabras de Melchior de Pandó: «-Curial, aquesta donzella pot haver nom Làquesis, mas ella és Àntropos, certament, e axí ho provarets per temps» (I, 85). Asimismo, el narrador presenta, como ya hemos visto, a Làquesis como una dama muy preocupada en todo momento por su aspecto físico, asunto que merece su condena explícita:

Làquesis, que no era stada a les vespres del torneig, vench en companyia de sa mare a les loges, en lo pus noble punt que ella $\cdot$ s pogué metre, e sí fonch molt loada de inextimable

${ }^{14} \mathrm{El}$ autor del Curial sustituye, como acabamos de comentar, la descripción de la joven por una alusión a la obra de Guido delle Colonne, cuya traducción al catalán se convirtió en una de las versiones de materiales pseudoclásicos más divulgadas. Por el contrario, en el Tirant Martorell copió precisamente el pasaje correspondiente en la descripción de Carmesina. La referencia a la obra de Colonne, que se repite en la escena final del matrimonio de los protagonistas, permite deducir la difusión de esta versión del mito troyano entre los lectores del Curial, al tiempo que establece un paralelismo explícito entre las heroínas de la novela y las del mito clásico.

${ }^{15}$ Los elegíacos, siguiendo la tradición literaria griega desde Homero, utilizan a menudo la figura de la bella Helena como paradigma de la belleza femenina, igualada o incluso superada, no obstante, por la mujer amada (Prop. II, 3, 32; Ovidio, Amores, I, 10, 1-2). Como acabamos de comentar, este modelo de belleza gozó de extraordinaria difusión a lo largo de los siglos gracias a la obra de Guido delle Colonne. 
bellessa, car tot lo seu studi era créxer la bellesa sua a tot son saber, car no era mestre de medicina, que abte fos, que ella no $\cdot 1$ tengués ocupat en ordonar e fer materials per mudar la pell, aprimar-la, e esclarir la cara, pits e mans. Pens yo que ella no creya que altre paraýs hi hagués sinó ésser bella e alegrar-se dels terrenals desigs ${ }^{16}$. (II, 186)

Y un poco más adelante adjunta como colofón a la descripción del combate de las bellezas femeninas uno de los escasos comentarios de tinte misógino que encontramos en la novela: «Ay, e com les conegué aquell gran philòsoph apellat Plató, quant dix que lo seny de les dones tot està en la bellesa, e, per contrari, la bellesa dels hòmens en lo seny!» (II, 187).

Pero más allá de moralistas y predicadores, la condena de la belleza artificial es un motivo también presente en los versos de los elegíacos, muy lejos, sin embargo, de la reprobación moral de la novela catalana ${ }^{17}$. Si Ovidio defiende que la belleza natural es la mejor (Amores, I, 14), Propercio afirma de modo contundente: «Nudus Amor formae non amat artificem» (I, 2, 8). Y la idea se reitera con frecuencia en sus versos: «Ut natura dedit, sic omnis recta figura est» (II, 18B, 25). Los elegíacos latinos descienden a detalles más concretos, se fijan en especial en sus críticas en el cabello y, como el caso de Làquesis, en el maquillaje: «Deme: mihi certe poteris formosa uideri» (Propercio, II, 18B, 29). En cuanto a Ovidio, parece inclinarse por la belleza natural en los Amores y las Heroidas, sin embargo, en su tratado sobre el arte del maquillaje, De medicamine faciei femineae ${ }^{18}$, así como en el Ars, junto a sus recetas para confeccionar tratamientos de belleza, desarrolla todo un concepto sobre el arreglo personal.

En cuanto a la tercera figura femenina del Curial, Càmar, se trata también de una muchacha de belleza proverbial, de la que el narrador no nos proporciona detalles concretos. La presentación del narrador es muy similar a la de las otras damas e incide en aspectos similares, como la edad o la fama de una belleza extraordinaria:

...tenia sa muller e una filla, ja de edat per ventura de quinze anys. E era tan bella, que, segons la fama que aquells qui la havien vista li feyen, no havia par en tot lo regne de Túniç. E, certes, no a tort, car si los ulls de Curial no eren enganats, no li ere atribuïda bellesa alguna que en ella no fos mills que ells no podien expressar. (III, 317)

${ }^{16}$ Se trataba de un reproche habitual en las diatribas de moralistas y predicadores como Eiximenis o sant Vicent Ferrer, quienes condenaban tajantemente la belleza artificial como aliciente para la lujuria y tentación que conduce al hombre al pecado (GRIFOLL, Isabel, 1993: «Per a una cosmètica del llibertí: trufes literàries al cap. CLXXXIX del Tirant lo Blanch», Actes del Symposion Tirant lo Blanc, Barcelona Quaderns Crema, p. 351; Op. cit. SIMÓ, p. 481).

${ }^{17}$ El tema de la cosmética y el arreglo y realce de la belleza femenina era muy conocido en la Antigüedad Clásica. Ya en Grecia se elaboraron tratados de cosmética, y en época de Ovidio, era un asunto que gozaba de gran popularidad. Ovidio probablemente conocía los tratados atribuidos a Cleopatra o el que Galeno cita como obra de la pornógrafa griega Elefántide, contemporánea del poeta. El propio Galeno distingue una cosmetiké techne, con una función de protección de la belleza natural, por tanto bella, frente a una commotiké techne, la cosmética creativa o maquillaje, rechazada y ridiculizada por el pensamiento griego, y más tarde por el romano, por anti-natural. La condena del maquillaje es, pues, secular, y ha estado vinculada a la crítica moralizante, aspecto que reflejan incluso los poetas elegíacos, que generalmente se oponen al pensamiento moral convencional (cf. RIVERO, Luis, [1996]: «Estructura y valor literario del poema ovidiano sobre cosméticos», La obra amatoria de Ovidio, ed. Arcaz, J.L. Laguna, G. Ramírez de Verger, A., Madrid, Ed. Clásicas, pp.125-126).

${ }_{18}$ Compartimos la opinión en este sentido de Badia \& Torró (cf. 2011, p. 601), quienes recientemente han destacado la proximidad de la novela catalana al Ovidio del De medicamine y la ausencia de condena a la cosmética femenina en el Curial. 
La fama de su belleza se extenderá pronto y será también la causa de los trágicos acontecimientos que seguirán:

La fama de la bellesa de Càmar pervench a les orelles del rey ${ }^{19}$, e tramés per Fàraig, e demanà-li de la bellesa de la sua filla.

Fàraig respòs que hom del món no podia dretament judgar en sos fills, e que a ell bella li paria, emperò poria ésser que no parria tan bella als altres. Per què lo rey li manà que la fes venir, que ell la volia veure. (III, 320)

$\mathrm{Al}$ igual que Güelfa y Làquesis, Càmar se siente rápidamente atraída por la belleza de $\mathrm{Cu}$ rial. El trato frecuente con Johan hace que la muchacha se fije en los encantos del bello cautivo, en especial de sus ojos: «'s pres esment de la bellesa del cors de Curial e de la resplandor dels seus ulls, e mirà-li la boca e totes les circumferències de la cara, e féu juyhí que en lo món pus gentil home no havia ne encara podia haver», belleza que supera incluso la de su padre Fàraig, «qui era judgat un dels bells hòmens de tot aquell regne, no egualava, ab tornes de molt, ab la bellesa de Johan» (III, 318). Con todo, de entre las protagonistas femeninas del Curial, parece claro que en Càmar el narrador ha concedido menor importancia a la belleza física, en favor de otros rasgos como la determinación, la virtud, la pasión amorosa o la honestidad.

La exaltación de la belleza de la amada llevaba a los poetas elegíacos a su identificación con la divinidad, la amada es concebida y tratada por el poeta como una diosa: es la puella diuina. ${ }^{20}$ Propercio antepone la belleza de su amada Cynthia a la de las diosas:

cedite iam, diuae, quas pastor uiderat olim

Idaeis tunicas ponere uerticibus! (Carmina, II, 2, 13-14)

Belleza con la que iguala a la mítica Helena:

post Helenam haec terris forma secunda redit. (Carmina, II, 3, 32)

Ovidio exclama:

Pace loquar Veneris, tu dea maior eris.

Per tibi tot iuro testes pompamque deorum

te dominam nobis tempus in omne peti. (Amores, III, 2, 60-62)

${ }^{19}$ La fama de la belleza de la heroína que se extiende por lugares lejanos es también otro motivo que se repite en la novela sentimental griega y que resulta esencial en el desarrollo de la trama de este tipo de obras. Lo mismo sucede con la defensa a ultranza de su virginidad (III, 320; 321), aunque en el Curial el motivo aparece entremezclado con elementos cristianos. Càmar, musulmana, en efecto, justifica ante su padre la negativa a un matrimonio con el rey de Túnez porque «yo he oferta la mia virginitat a Déu, e no la y toldré per cosa del món» (III, 321). De cualquier forma, en la novela sentimental antigua, la conservación de la castidad de los amantes es un motivo típico. En ocasiones, alguno de los protagonistas mantiene la virginidad, tal como pretende Càmar, a modo de promesa, como sucede en la novela de Heliodoro o de Aquiles Tacio. En esta última, por ejemplo, Leucipa se consagra a la diosa Ártemis -identificada tardíamente con la luna- y permanecerá virgen por decisión propia, a pesar de las muchas peripecias, hasta su boda con Clitofonte. La virginidad de la protagonista, como en el caso de la joven mora, se verá amenazada pero salvaguardada finalmente, y aquí sí que la historia de Càmar se distancia absolutamente de este tipo de obras, antes del final feliz de los amantes.

${ }^{20} \mathrm{La}$ belleza ya entre los autores griegos, en efecto, es considerada como un reflejo de la belleza divina: «La beauté, don des dieux, élève au-dessus de la condition humaine qui l'a reçue et ainsi le rend semblable ou même parfois supérieur a la divinité. Comme le plus beau compliment qui puisse être adressé à la femme aimeé, c'est de la comparer à une déesse, les poètes érotiques ont abondamment usé de cette comparaison » (SАвот, A. F., [1976]: Ovide poète de l'amour dans ses oeuvres de jeunesse, Paris, Ophrys, p. 388). El motivo, presente ya en la literatura griega arcaica, se difunde ampliamente en la poesía alejandrina y en la novela sentimental griega, y a través de la comedia se introduce en las letras latinas. 
Entre los poetas elegíacos latinos, es Ovidio quien utiliza muy a menudo el motivo de la divinización de la amada, a la cual con frecuencia, como en el fragmento anterior, se dirige como dea. En este autor, a diferencia de otros poetas, más que una domina de la cual el poeta es esclavo, la amada se convierte en una auténtica dea a la que el poeta adora. ${ }^{21}$ También Petrarca recoge con frecuencia el motivo en sus versos de amor, y así lo proclama Francesco ante Agustín en el Secretum: «in cuius aspectu, siquid usquam veri est, divini specimen decoris effulget (...) cuius nec vox nec oculorum vigor mortale aliquid nec incessus hominem representat» (III, 10). ${ }^{22} \mathrm{El}$ eco de esta idea aún se percibe igualmente en las palabras que Curial dirige al anciano Melchior de Pandó para pedirle noticias de su señora, en un fragmento pleno de alusiones mitológicas:

- A, Melchior, pare meu! ¿E què és de la deessa del món? ¿E sí li recorda de mi? A, Cupido, les armes del qual port ficades en lo meu cor! Yo mir sovén en los cels e en lo terç contemple la tua mare, la qual ab los raigs luminosos de la sua gran resplandor sol il-luminar aquest sobres tenebrós cor prometent-me bona sperança. (I, 76)

La misma idea se percibe en clave cristiana en la alusión del narrador a la belleza de Làquesis y Festa:

O celestial bellesa! O angelicals cares! ${ }^{23}$ ¡E com se delità lo Senyor e Creador de natura humana, en crear aquestes dues donzelles, segons la opinió mundana! (II, 187)

Sin embargo, se trata tan solo de un aspecto puntual en la novela catalana, que apunta a otro tipo de relación amorosa como ejemplo virtuoso, más humana, la que alcanzan al final de la obra Curial y Güelfa, y a otro modelo femenino. El autor anónimo de la novela resalta más bien en sus protagonistas femeninas otros rasgos. En efecto, junto a una extraordinaria belleza, las damas del Curial se destacan por su gracia y distinción, así como por su cultura y refinamiento. ${ }^{24}$ Son estos precisamente los rasgos más sobresalientes de las amadas de la elegía latina:

non ego sum formae tantum mirator honestae,

nec si qua illustris femina iactat auos,

${ }^{21}$ Op. Cit. SАвот, 1976, p. 393. Ello explicaría el éxito del poeta de Sulmona en la época medieval, cuando la literatura cortés retoma el motivo de la divinización de la amada y el caballero se convierte en el esclavo de la dama a la que honra como a una diosa: «Les romans courtois n'ont fait que développer à l'extrême une tendance dejà contenue implicitement dans l'oeuvre d'Ovide. Les libertins distingués des deux sexes de l'èpoque augustéenne -et surtout les femmes- ont dû prendre pour bréviaire les poèmes de jeunesse d'Ovide pour y puiser des règles de conduite, comme les femmes de XII siècle cherchaient dans les romans courtois l'art de se conduire dans la vie courante selon les regles du code chevaleresque, comme plus tard les hommes et les femmes trouveront dans l'Amadís de Gaule ou dans l'Astrée le canon des belles manières et l'art de faire face selon l'honnêteté aux differentes situations dans lesquelles les place la vie mondaine » (Sabot, 1976, p. 394).

22 Cf. Petrarca, F. (2011): Mi secreto. Epístolas. Ed. bilingüe ARQUÉS, Rossend. Madrid, Cátedra.

${ }_{23}$ Estamos ante un motivo estilnovista de raiz clásica. Igualmente Ovidio en sus versos compara el rostro de su amada Corina al de una divinidad poderosa: «...perque tuam faciem, magni mihi numinis instar» (Amores, III, 11, 47).

${ }^{24}$ Sobre la consideración de la cultura y la educación en la mujer en la sociedad romana, cf. López, Aurora (1994): No solo hilaron lana. Escritoras romanas en prosa y verso, Madrid, Ediciones Clásicas; Pomeroy, Susan (1987): Diosas, rameras, esposas y esclavas, Madrid, Akal, pp. 193-199; Cantarella, Eva (1996): La calamidad ambigua. Condición e imagen de la mujer en la antigüedad griega y romana, Madrid, Ed. Clásicas. Esta estudiosa muestra abundantes ejemplos de mujeres romanas destacadas por sus logros intelectuales y artísticos, y de su valoración social: Cornelia, madre de los Gracos, Laelia u Hortensia o Cornelia, esposa de Pompeyo. El testimonio de escritores, filósofos y poetas, en especial los elegíacos, corrobora esta idea. Aurora López, por su parte, evoca una galería de mujeres de la Roma Antigua que destacaron por su producción literaria. 
me iuuet in gremio doctae legisse puellae ${ }^{25}$. (Propercio, II, 13, 9-11)

me laudent doctae solum placuisse puellae. (I, 7, 11)

Es este también un rasgo que comparten con el protagonista masculino, excelente caballero, quien, además, y a pesar de su modesto origen, sobresale desde muy joven como hombre cultivado. Como sabemos, cuando el joven Curial cae en el olvido del marqués, para aprovechar el tiempo «aprés gramàtica, lògica, rectòrica e philosophia, e fonch valent home en aquestes sciències, e axí mateix poeta molt gran, en tant que en moltes partides, sabent-se la sua sciència, devench molt famós e era tengut en gran stima» ${ }^{26}(\mathrm{I}, 46)$, e igualmente «...tornà molt prudent e abte; car tantost fonch molt bell cantador, e aprés sonar esturments - de què devench molt famós-» (I, 48). Sobresale en la danza (I, 75) y domina el arte de la música y del canto, de manera que su canto no parece sino «veu angelical e dolçor de paraýs» (I, 110 $)^{27}$. Se ha sugerido que la actividad como cantor, censurable desde la moral de la época, de Curial es precisamente uno de los motivos de su castigo ${ }^{28}$, sin embargo el narrador describe cómo el joven Curial aprovecha su juventud en la corte del marqués y adquiere ya gran fama como «poeta molt gran» $(\mathrm{I}, 46)$. Asimismo, es justamente durante el período de cautiverio y regeneración moral cuando Curial compone su canción de amor a Güelfa. Ya hemos analizado en otro lugar la relevancia de la danza, la música y el canto en el lenguaje de los elegíacos y sus paralelos en la novela catalana ${ }^{29}$. Los poetas latinos subrayan continuamente el atractivo erótico de la danza y la música e invitan a los jóvenes a admirar e incluso a servirse de estas habilidades típicamente femeninas en el juego de la seducción. Las amadas de los poetas latinos sobresalen en el conocimiento de la poesía, la danza, el canto y el dominio de los instrumentos musicales (Prop. II, 3, 17-22; II, 19, 15). En la novela catalana, Làquesis, la dama más bella y seductora de la obra, destaca por su gracia, que despierta la admiración general: «Miraven-la tots, e ·ncenían-se de la su· amor, car, ultra la bellesa que havia, era tan graciosa, que no la veya persona qui d'ella no s'altàs» (II, 186). El propio Curial, extasiado, admira su encanto al servir el vino en el banquete y bebe en la copa que la joven le ofrece $(\mathrm{I}, 80)^{30}$.

${ }^{25}$ Como veremos más adelante, Càmar y Johan pasarán la mayor parte de su tiempo juntos precisamente leyendo y comentando poesía latina.

${ }^{26}$ La aceptación de la fama y la gloria mundana como premio a la virtud y a los méritos en la vida terrena deviene una actitud frecuente entre los humanistas, recuperada del mundo clásico, en abierta contradicción con la tradicional condena del orgullo y la vanagloria de la doctrina cristiana, según la cual esta recompensa estaba reservada para la vida venidera. La lucha entre la humildad cristiana y el deseo de gloria mundana, que había atormentado a Petrarca y a Boccacio, será superada por los humanistas del Cuatrocientos, que alientan abiertamente en sus escritos el deseo de gloria.

${ }^{27}$ En estos aspectos Curial recuerda a uno de los héroes de la novela antigua, Apolonio, protagonista de la Historia Apollonii regis Tyri, personaje que sobresale por su dimensión cultural y sus habilidades artísticas. Cf. FernándeZ-Savater, María Victoria (2005): Temas y motivos novelescos. La Historia Apolonii regis Tyri, Huelva, Servicio de Publicaciones. Universidad de Huelva, p. 97.

${ }^{28}$ Cf. CoRTÉs, Matilde (1996): «La coherència iconogràfica de la segona visió mitològica de Curial», $R L L C G V, \mathrm{~V}, \mathrm{p} .49$.

${ }^{29}$ Gros, Sònia (2011): «Escenes de seducció en el Curial e Güelfa. Una lectura des dels clássics», L’Humanisme en la Corona d' Aragó (en el context hispànic i europeu), Maryland, Scripta Humanistica, pp. 101-124.

${ }^{30}$ Hay que recordar que el motivo de los amantes que beben de la misma copa aparecía, con frecuencia, en la literatura amorosa grecolatina, de la comedia (Bacchides 49) y la novela sentimental (Leucipa y Clitofonte II, 9), a la poesía de los elegíacos (Ars, I, 575-576; Am., I, 4, 31-32) [Gros 2011]. 
En cuanto a Güelfa, al comienzo de la obra cuando el narrador la presenta destaca, junto a su sobresaliente belleza, otras cualidades que la caracterizan: «Era aquesta Güelfa molt sàvia ${ }^{31}$, e suau, e temprada en sos moviments» (I, 45). El calificativo, aunque sin más detalles, se repite más adelante: «...lo marquès hach molt gran plaer, e ·n parlà ab ella; mas la Güelfa, axí com aquella qui era molt sàvia senyora...» (I, 107), y se aplica igualmente a su criada Festa, «aquella sàvia donzella» (II, 212). Curial, su enamorado, no se queda atrás en este aspecto. De entre las razones por las que Güelfa se enamora de él, el narrador destaca que «no havent esguart a claredat de sanch ne a multitut de riqueses, entre $\cdot 1 \mathrm{~s}$ altres li plagué molt Curial, car veent-lo molt gentil [de] la persona, e assats gentil de cor, e molt savi segons la sua edat, pensà que seria valent home si hagués ab què» $(\mathrm{I}, 46)$. Igualmente, Melchior, su protector, «home molt savi, secret e valerós» (I, 46), le aconseja en diversas ocasiones «que sies savi».

Hasta aquí la caracterización de los personajes de la novela catalana no difiere en exceso de la que encontramos en muchos de los relatos del Decameron, obra que sustenta la construcción narrativa del Anónimo, quien reutiliza en su propia obra numerosos fragmentos del italiano ${ }^{32}$, y cuya prosa le sirve de modelo estilístico. ${ }^{33}$ Así, en el relato II, 8 el conde de Amberes es presentado como «gentile e savio uomo» (p.260) ${ }^{34}$. A ello se añade que era «del corpo bellissimo» $\mathrm{y}$ «tanto piacevole e costumato quanto alcuno altro gentile uomo il più esser potesse». Además, «era il più leggiadro e il più dilicato cavaliere» (p. 260) de su tiempo. En I, 5, la marquesa de Monferrato es presentada como «donna savia e avveduta» (p.91). Ghismonda, protagonista de la novella IV, 1 , era «savia più che a donna per aventura non si richieda» (p. 472). La esposa de Messer Torello, en X, 9, se comporta «sì come savia e costumata» (p. 1229). La propia Ghismonda, Espina o la amante de Cabestany argumentan con notable elocuencia sus decisiones, como harán Làquesis o Càmar en la novela catalana.

Pero cuando, más adelante, el rey de Francia alaba las virtudes de Curial, resalta este aspecto, vinculando ya directamente su carácter de savi al conocimiento, más aún, a la excelencia del caballero en determinadas disciplinas -especialmente cultivadas por los humanistas- como la filosofía, la poesía o la oratoria: «...és molt abte e virtuós, savi e de gran e notable consell; però no me'n maravell, car entre los grans philòsofs, poetes e oradors, ${ }^{35}$ veig que és tengut en gran stima» (II, 247). E insiste

31 El DCvB documenta el término en los autores medievales con el doble significado de «que té ciència, coneixements molt vastos», así como «que sap obrar amb seny».

${ }_{32}$ Cf. ButinyÀ, Julia (2001): Tras los orígenes del Humanismo: el «Curial e Güelfa», Madrid, UNED; Stocchi, Manuela (1995-1996): «Curial e Güelfa i il Decamerone». Boletín de la Real Academia de Buenas Letras de Barcelona 45, pp. 295-315.

${ }^{33}$ Espadaler, A. M. (2003): Novelas caballerescas del siglo XV, Madrid, Espasa Calpe.

${ }^{34}$ Citamos a partir de la edición de Vittore BRANCA (1991): Decameron, Torino, Einaudi.

35 En De sui ipsius et multorum ignorantia (1367) Petrarca censura la ignorancia de la filosofía escolástica y defiende la causa de los studia humanitatis argumentando que el conocimiento de la literatura clásica es camino de perfección y al tiempo fuente de bondad. En este planteamiento se hermanan retórica y filosofía moral a la sombra de la literatura, como ejemplifica la figura modélica de Cicerón. Por otra parte, en cuanto a la oratoria, debemos recordar que, asimismo, la elocuencia era una virtud muy considerada entre los poetas elegíacos latinos, que habían recogido la idea de la literatura griega. Calderon observa que «el tópico erótico consistía en que el amante que deseaba lograr los favores de una muchacha debía tener, en primer lugar, una habilidosa retórica. Así lo podemos ver, por ejemplo, en las Anacreónticas (fr. 52 Brioso) y en Apolonio de Rodas (Argon. 3, 458; 3, 1102; 4, 359), donde Jasón se mues- 
de nuevo el rey de Francia a propósito de Curial, vinculando ahora su excelencia al estudio y al trato con los libros, nuevamente rasgos distintivos de los humanistas: «...si ·l volets en cambra cantar, dançar e solaçar curialment, dich-vos que algú dels altres no -s pot egualar ab ell; e, partit d'aquí, no lexa l'estudi, ans tracta tan reverencialment los libres ${ }^{36}$, que tots quants lo conexen ho han a gran maravella» (II, 247).

En la misma línea, cuando Curial es coronado de laurel por Apolo, ${ }^{37}$ el dios se expresa en términos similares ponderando su dominio de la poesía y de la oratoria: «-Millor e pus valent entre los cavallers, e major de tots los poetes e oradors ${ }^{38}$ que vuy són. E comunicà-li tota la sapiència de la sua deïtat, en manera que Curial fonch informat axí de les virtuts e estrenuiitats dels cavallers, com de la composició e ordinació dels libres»» ${ }^{39}$ (III, 309).

tra como un consumado orador para atraer a Medea» (CALDERón DORDA, Esteban [1997]: «Los tópicos eróticos en la elegía helenística», Emerita, LXV, p. 7). Y Ovidio recuerda el ejemplo de Ulises y la causa de su atractivo: «Non formosus erat, sed erat facundus, Ulixes / et tamen aequoreas torsit amore deas» (Ars, II, 123-124).

${ }^{36}$ Este comentario del rey de Francia sobre Curial es sumamente revelador acerca de la sensibilidad humanista del autor de la novela catalana. La valoración de libro aparece, en efecto, como uno de los rasgos más característicos del movimiento humanista. «No existió humanismo sin libros», afirma Davies (DAVIES, M. [1998]: «El libro humanístico en el Cuatrocientos», KrAYE, Jill (ed.), Introducción al humanismo renacentista, p. 73), quien subraya el papel del libro en la construcción y difusión del movimiento. Muchos humanistas, como hemos apuntado anteriormente y como hará Curial tras la admonición definitiva de Baco, dedicaron gran parte de sus esfuerzos a la búsqueda y recopilación de volúmenes, en especial de autores clásicos. Es también la época de la creación de grandes bibliotecas particulares de dignatarios religiosos o políticos. Cabe recordar, igualmente, la pasión de Alfonso el Magnánimo, con cuyo entorno la crítica relaciona la gestación de la novela, por los libros, y el hecho de que el libro, abierto como si alguien lo estuviera leyendo y representado con todos sus detalles, es uno de los emblemas más utilizados en la decoración de los códices de la biblioteca napolitana del Magnánimo, una de las más ricas de su época (cf. Alcina Franch, José [2000]: La biblioteca de Alfonso V en Nápoles, Generalitat Valenciana).

${ }^{37}$ Este tipo de escenas contaba con una tradición bien consolidada entre los autores clásicos. La aparición de Apolo en sueños llegó a ser habitual entre los poetas de la época de Augusto como fórmula de expresión alegórica de la consagración poética. Asimismo, Otros dioses pueden igualmente asumir este papel de divinidad oracular y para otros fines literarios como sucede en Ponto III, 3, donde Cupido, descrito físicamente con todo lujo de detalles, se le aparece en sueños a Ovidio e, interesándose por circunstancias de su vida particular, lo reconforta y anima a soportar el destierro. Cf. NAVARRo, Fernando [1996]: «Ingenium dominae lena mouebit anus. La auara puella en los Amores de Ovidio», La obra amatoria de Ovidio, ed. ArCAZ, J.L., LaGUnA, G., Ramírez de Verger, A., Madrid, Ed. Clásicas, p. 87.

${ }^{38}$ Hay que remarcar que estamos ante uno de los rasgos más característicos del movimiento humanista, la relevancia de la elocuencia. Las primeras generaciones de humanistas italianos, como Bruni, defienden que las disciplinas de los studia humanitatis deben entenderse principalmente en clave retórica (cf. González Rolán, T, Moreno, A. SAquero P. [2000]: Humanismo y teoría de la traducción en España e Italia en la primera mitad del siglo XV, Ed. Clásicas, Madrid, p. 119). «La sabiduría debe ir unida a la elocuencia, según gustaban de repetir muchos humanistas, y según decía Ermolao Barbaro polemizando con G. Picco della Mirandola», recuerda P.O. Kristeller (1980): «El territorio del humanista», Historia y Crítica de la Literatura Española, 2, ed. F. Rico y F. López Estrada, Barcelona, Crítica, p. 34). Y Lorenzo Valla en De vero bono (1432) compara la filosofía a un soldado raso o un sargento que sirve a la oratoria como a un general, ya que los oradores saben mucho mejor que los dialécticos cómo discutir un problema, pues la oratoria es, en efecto, la reina de las cosas. Este mismo autor, en las Dialecticae disputationes (1439), presenta a Quintiliano como autoridad en dialéctica e ilustra, de esta manera, la tendencia humanista de subordinar la lógica a la retórica: «la dialéctica de Valla es un intento por reformar la lógica de Aristóteles y de los últimos escolásticos, y la finalidad de esta reforma es simplificar la lógica como un todo, reducirla al uso clásico, y enlazarla -si no reducirla- a la disciplina de la retórica, que constituía el núcleo profesional y el tema favorito del saber humanista» (Kristeller, P.O. [1985]: Ocho filósofos del Renacimiento italiano, México, FCE, p. 54).

${ }^{39}$ Creemos que, por todo lo que acabamos de comentar, el modelo de educación que ejemplifica Curial en la novela supera la simple cortesía propia de los caballeros medievales y se aproxima a 
Elocuencia, la de Curial, destacada explícitamente por el narrador, que, sin embargo, al no ir acompañada de un comportamiento virtuoso en el amor, no será suficiente para obtener el perdón de Güelfa por su ingratitud, como atestigua el comentario del narrador:

E, si tot era molt eloqüent e gran orador, certes ací havia perduda e perdé la sciència $\mathrm{e}$ tot lo saber, que, com més treballava en escusar-se, paria que pus fort ell mateix s'acusàs, e, de ço que no era res, feya crim e mortal pecat. Vejats què cosa és l'ome com pert la gràcia. (II, 265)

El comentario sintetiza la subordinación de la ciencia y el conocimiento, la poesía y la oratoria, a la virtud moral, y la preponderancia del componente ético de la novela.

Asimismo, entre las virtudes que los elegíacos apreciaban en la mujer amada, cobra especial importancia, como hemos comentado, el dominio del canto y de los instrumentos musicales, tal como aconseja explícitamente Ovidio (Ars, III, 311-316). Con el canto intenta en vano Curial, en su retorno como mendigo a Monferrat, persuadir a Güelfa de la sinceridad de sus sentimientos con la canción -la cançó de l'orifanyque expresamente compone para ella durante su cautividad (III, 347-348). La música y el canto contribuyen a crear un ambiente especial en esta escena clímax en la trama de la novela, en la que la alusión al conocimiento de diferentes lenguas hace pensar en un, evidentemente, falso mendigo, pero sin duda también en una dama a su altura intelectual: estamos, de nuevo, ante una docta puella. Son, en efecto, principalmente los personajes femeninos de la novela quienes demuestran en sus conversaciones y en su actitud vital un poso de lecturas muy significativo en cuanto a las preferencias literarias del Anónimo y a sus modelos morales: los clásicos latinos y los humanistas italianos. De forma explícita, Virgilio y Boccaccio, en dos historias paralelas, las de Dido y Ghismonda, heroínas, ambas, que se suicidan ante la imposibilidad de consumar sus relaciones amorosas.

De entre las protagonistas femeninas es Càmar el personaje en quien el autor, paradójicamente, ha acentuado los rasgos de mujer cultivada. La soledad de la bella joven, recluida en casa por su celoso padre, favorece el contacto con los cautivos y en su relación de nuevo juega un papel interesante la música ${ }^{40}:$ «...sallint de casa se n'entrava en aquell ort, e ab aquells catius, qui maravellosament cantàvan, tot lo dia s'estava, (...) Cantava molt bé Càmar, e Johan mostrà-li moltes cançons, e ab acorts

un nuevo modelo de caballero letrado. Espadaler, en su estudio sobre la novela catalana, describe la educación de un caballero real del siglo xv, Jacques de Lalaing, de la cual subraya su conocimiento, elemental, del latín y el francés, la práctica de juegos nobles y la preparación para la guerra y para el amor, de manera que el caballero francés, ya adulto, destaca en el juego, el torneo, la caza y, en el ámbito literario, por sus composiciones amorosas (op. cit. Espadaler, 1984, pp. 209-212). Una educación similar, aún más centrada en las armas, es la que recibe Pero Niño, según narra El Victorial. En definitiva, ambas se ajustan con matices diferentes al modelo cortés medieval. Las diferencias con Curial son sumamente significativas.

40 Tenemos un precedente de esta situación en la novela antigua. En efecto, en la Historia Apollonii regis Tyri, la princesa se enamora del protagonista a causa de sus habilidades musicales. 
cantava ab ella» (III, 318). El narrador, además, nos ofrece otro dato muy concreto y sumamente interesante sobre el personaje: la muchacha lee poesía, y poesía latina, aunque, matice, traducida y comentada en su lengua:

E, com Càmar dels catius se partia, legia l' Eneydos de Virgili ${ }^{41}$-lo qual ella en lengua materna tenia, ben glosat e moralizat, car son pare lo havia haüt del rey-, e molts altres libres, ${ }^{42}$ en què la donzella passava temps; e era tan entesa, segons la sua tendra edat, que açò era una gran maravella. (III, 319)

Efectivamente, observamos que en el Ars Ovidio ya aconsejaba a las jóvenes conocer la poesía griega y latina. De entre las obras y autores sugeridos, el poeta precisamente destaca de forma elogiosa la lectura de la Eneida:

...Sit tibi...nota....

Et profugum Aenean, altae primordia Romae, quo nullum Latio clarius extat opus. (Ars, III, 337-338)

Creemos que este fragmento de la novela catalana es sumamente interesante y, desde nuestro punto de vista, ilustra literariamente una de las ideas preferidas de los humanistas italianos, la de que el saber y la elocuencia estaban inextricablemente unidos con los estudios clásicos. Como observa Kristeller, los humanistas tenían la firme convicción de que tanto el saber como la elocuencia, tanto el contenido como la forma de los textos, dependían del estudio e imitación de los autores griegos y latinos antiguos ${ }^{43}$. La lectura de estos textos clásicos será precisamente el nexo de unión definitivo en la relación entre Càmar y el cautivo:

E Johan, que sabia molt bé tot lo Virgili e los altres libres, li declarava moltes coses que ella no sabia ne entenia; e yo us dich que de ço que ella podia pagava bé lo maestre. Parlava Johan molt bé aquella lengua, e Càmar mostrà-li legir e scriure, en manera que, quant Fàraig no y ere, ella e Johan nulls temps se partien. (III, 319)

${ }^{41}$ Sobre la dependencia del episodio de Càmar y el cautivo respecto a la Eneida, (y la versión que de ella elabora Petrarca en las Seniles, que después transmite asimismo Boccaccio en su Genealogia), y la interpretación de la historia de Curial como réplica y superación de la de Eneas, cf. BASTARDAs, Joan (1987): «El suïcidi literari de Càmar. Una nota sobre el primer humanisme català en la novel-la Curial e Güelfa», Estudis de llengua i literatura catalanes, XIV, Miscel-lània Antoni M. Badia i Margarit, Barcelona, PAM, pp. 255-263, y Turró, Jaume (1991): «Sobre el Curial, Virgili y Petrarca», Miscel-lània Joan Fuster. Estudis de llengua i literatura a cura d'Antoni Ferrando i d'Albert G. Hauf, III, PAM, pp. 149-168. Por otra parte, María Rosa Lida en su estudio sobre la figura de Dido en la literatura española, subraya el ascendiente de la Eneida en el período medieval (Lida, M. R. [1974]: Dido en la literatura española. Su retrato y su defensa, Londres, Tamesis Books Limited, p. 4 ss). Y señala la novela catalana como la primera recreación de la historia de Dido a partir de su versión no virgiliana (op. cit. p. 111).

42 Otros especialistas han sugerido que las heroínas del Curial, en especial Càmar, conocen bien las Heroidas, y las utilizan como modelo para sus propias cartas al caballero. Además, transforman su admirado modelo superando la pasividad de las heroínas de Ovidio y convirtiéndose, mediante el acto de escribir, en las rectoras de la vida de Curial: «En el caso de Càmar, la lectura de la versión de Dido presentada en las Heroidas será lo que propiciará la relectura crítica que Càmar efectúa de la Eneida de Virgilio» (PIERA, Montserrat [2001]: «Lectores y lectoras de Boccaccio en Curial e Güelfa», eHumanista 1, p. 93). Y a propósito de Fiammetta, comenta esta especialista: «Este personaje femenino ficticio se convertirá en modelo y punto de referencia (tanto para emular su comportamiento como para tomar ejemplo de sus errores) para las lectoras del siglo XV que se familiarizarán también con las Heroidas de Ovidio a través de la lectura boccacciana».

${ }^{43}$ Op. cit, 1980, p. 35. 
La joven, por tanto, también actúa como maestra del cautivo enseñándole a leer y escribir su propia lengua y, un poco más adelante, demostrará sus conocimientos de los autores clásicos y una elocuencia considerable, apelando a su autoridad o aludiendo a numerosos ejemplos del mito, como cuando, por ejemplo, los utiliza ante su madre en defensa de su argumentación, o con la mención a Catón, paradigma de la libertad y virtud, de quien la joven se declara «dexebla» (III, 329). Fàtima, su madre, asimismo, también apoya su argumentación en ejemplos clásicos:

¿E penses tu que Cató, com se fonch ferit en Útica, e ab lo ferro féu camí per on fugís de Cèsar la sua espaventada ans esglayada ànima, no ·s penedís de haver-se donada mort, sinó que no ho pogué dir en la fi? ¿E quiny mal féu a Cèsar? ¿E libertat penses que sie la mort? Carçre escur e tenebrós la pots apellar, e exili sens sperança de retorn (III, 329) ${ }^{44}$.

Conversación que consideramos extremadamente llamativa entre dos mujeres moras, que, conviene recordar, viven escondidas lejos de la ciudad, apartadas de la compañía de todos excepto de los dos cautivos cristianos.

Sin embargo, el ejemplo más significativo de los conocimientos de cultura clásica de la joven mora lo constituye, en nuestra opinión, su largo parlamento antes de morir (III, 339-340). Càmar, en efecto, no se contenta con una lectura pasiva de la Eneida, sino que recrea de modo personal en su propia actuación el comportamiento de la reina fenicia. La joven mora invoca a Dido antes de morir, recuerda los motivos que, según Virgilio ${ }^{45}$, la llevaron al suicidio y contrapone la situación de la reina de Cartago a la suya, fruto de una decisión meditada y provocada, no por el abandono de su amante, sino por el deseo de evitar el matrimonio con un hombre al que no ama. En un momento tan relevante de la novela, justo antes de su suicidio, Càmar justifica, ante sus parientes y Curial, su acción, y lo hace apelando a un ejemplo de la literatura latina, que interpreta, además, con criterio propio. Resulta evidente, por tanto, que con su relectura de la Eneida, el

${ }^{44}$ Muy recientemente Júlia Butinyà ha analizado los diálogos de ascendencia clásica de la novela, entre ellos este que mantienen Fàtima y su hija, desde la perspectiva del influjo de Dante y la caracterización de dos de los personajes femeninos de mayor relieve en la obra, Càmar y Güelfa (op. cit. 2011).

${ }_{45}$ En este momento clave de la novela, Càmar recurre de nuevo a la versión virgiliana de la historia de Dido, en aparente contradicción con el argumento esgrimido por Apolo en el episodio del juicio literario al comienzo del libro III de la novela, en que se alude a la falta de realismo histórico de esta versión, contraponiéndola a la de San Jerónimo -posiblemente, a partir de la versión de Petrarca, como propone el estudio de Turró (1991)-: «Axò mateix ha fet Virgili (...) dient, entre les altres, Dido, reyna de Cartago, ésser-se morta per Eneas; la qual cosa no fonch ni és veritat, car Eneas nulls temps viu Dido, ne Dido Eneas, car de l'un a l'altre hach prop de tres-cents anys» (III, 308). María Rosa Lida recuerda la convivencia a lo largo de los siglos de estas dos versiones sobre la reina de Cartago: «Junto a la rica influencia del libro IV de la Eneida aparece en la Europa medieval y persiste vigorosamente en España durante todo su Siglo de Oro la versión de la leyenda de Dido anterior a la virgiliana, que nada sabe de sus amores con Eneas» (op. cit. Lida, 1974, p. 57).

Esta versión más antigua aparece por primera vez en la Historia de Sicilia e Italia de Timeo (340-256 a.C.) y fue difundida por Justino a fines del siglo II o principios del III en un relato de sus Historias filípicas. Ello explicaría, según Lida, el arraigo de esta versión en la Península ya que Justino se convirtió en uno de los historiadores preferidos de los autores hispanos (op. cit., Lida, 1974, pp. 59-61). Otros autores tardorromanos como Servio o Macrobio, de gran predicamento en la época medieval, transmiten asimismo la forma no virgiliana de la historia de Dido y contribuyen extraordinariamente a su difusión posterior. La formulación de la historia de la Dido casta se ajustaba a la mentalidad verista dominante en el mundo medieval y fue aprovechada por la literatura eclesiástica como paradigma de viuda ejemplar. Así lo entiende Tertuliano, quien la califica de «integrae feminae Didoni» (De anima, 33), y San Jerónimo, autor revalorizado por los humanistas por su actitud de sincretismo de las tradiciones cristiana y clásica, con su célebre «maluit ardere quam nubere» (Contra Joviniano I, 43). 
Anónimo supera en este episodio la simple alusión erudita lejos de una ornamentación superficial y, por el contrario, imbrica con total coherencia y de forma explícita el hipotexto virgiliano, quizás mediatizado por la versión de Petrarca, en su propia narración.

En su estudio sobre la presencia de Dido en la literatura española, María Rosa Lida señala los tres motivos más repetidos en la recreación de la historia: la escena de la cueva, la partida de Eneas y la espada del héroe ${ }^{46}$. Observamos, por nuestra parte, que la novela catalana se nos muestra una vez más como una reinterpretación personalísima del episodio de Dido y Eneas. El encuentro amoroso de los protagonistas está ausente en nuestro relato, dada la función ejemplar de este episodio en el conjunto de la novela catalana; la muerte de la heroína se produce por otro procedimiento tras el intento frustrado de darse muerte con un coltell $^{47}$; por último, la escena virgiliana en que Dido contempla cómo su amado se aleja, es sustituida por una despedida explícita de la protagonista en que ella expone los motivos de su determinación apelando a Dido.

Si el Anónimo subraya en Càmar su dimensión como lectora de los autores clásicos, los grandes escritores humanistas asoman igualmente en las lecturas de los personajes femeninos de la obra. Làquesis, la dama más seductora de la novela catalana, que se singulariza por su encanto personal, fruto de una extraordinaria belleza y del magnetismo de su mirada, aparece, asimismo, como una buena conocedora de los textos sentimentales al uso del momento, los de Boccaccio, y se muestra capaz de asimilar conscientemente su contenido y adaptarlo a su propia situación amorosa. En el libro II, en efecto, encontramos una conversación entre Làquesis y su madre en que ambas recurren, para defender sus argumentos, a los personajes de una de las novelle del Decameron, Ghismonda y Guiscardo, cuya historia era ampliamente conocida en la época. El trasfondo de esta narración boccacciana en la novela catalana ya fue reconocido por Farinelli y los primeros estudiosos de la obra, y es claramente identificable en el planteamiento amoroso del relato catalán, así como en diversos rasgos de la pareja protagonista ${ }^{48}$. Pero, como vemos, el Anónimo explota intensamente el texto decameroniano en diferentes niveles de su narración y es quizás por ello que deja constancia explícita en su propia obra de la presencia boccacciana. Insistimos, por tanto, en que nuestra novela muestra una colección de personajes femeninos cultivados,

esos personajes femeninos que leen y discuten con avidez los textos de los autores clásicos y de los escritores humanistas, a pesar de tratarse de una actividad condenada por la Iglesia y por los moralistas, los cuales defienden que la mujer solamente debería leer obras de devoción y no textos profanos ${ }^{49}$.

Este, en nuestra opinión, es uno de los rasgos más destacados de los personajes femeninos de la novela, probable reflejo de un incipiente cambio de mentalidad en la sociedad del momento. La presencia de mujeres cultivadas, de doctae puellae, censurable y prácticamente inexistente en el período medieval ${ }^{50}$, constituye uno más de los rasgos humanísticos de nuestra obra que la aproxima a los autores clásicos.

46 Op. cit. LIDA, 1974, p. 24.

47 Hemos sugerido (op. cit. GROS 2012, pp. 230-231) la vinculación del suicidio de Càmar con el de la amante de Guillem de Cabestany en la novella IV, 9 del Decameron, muestra de la riqueza de la cultura literaria del Anónimo y de la imbricación coherente de fuentes diversas en su propia obra.

48 Op. cit. ButinYÀ, J. (2001); STOCCHI, M. (1995-1996).

49 Op. cit. Piera, M. (2001), p. 92.

${ }^{50}$ Cf. Cantavella, R. (1988): «Lectura i cultura de la dona a l'Edat Mitjana: opinions d'autors en català», Caplletra, 3, p.113. El inventario de Hillgarth, por su parte, documenta en Mallorca, entre 1229 y 
Si la imagen de la mujer como puella docta que nos ofrece el Anónimo se distancia de la visión femenina al uso dominante en el período medieval, se muestra más cercana, por el contrario -salvando las evidentes distancias de tono e intencionalidad entre las obras- a la que encontramos en humanistas vinculados a la corte napolitana del Magnánimo como Antonio Beccadelli. El Panormita, en efecto, esboza en el Hermaphroditus su ideal de mujer, al estilo elegíaco: una puella diuina -«pulcrior illa deo» (II, 13, 23) $-^{51}$, que anteponga la poesía a la riqueza -«divitibus vates, praeponat carmina gazis» (II, 13, 20)-, que sobresalga en el arte de la danza y el canto -«quae thiaso et cantu docta sit ante alias» (II, 13, 31) - y a quien pueda dedicar sus poemas. Y, aún más significativo, en otra composición, la II, 23, testimonia la afición de su amada por la lectura de los textos de los poetas clásicos: el poeta, en efecto, solicita a su amigo Galeazzo que le consiga un ejemplar de los poemas de Catulo para poder así complacer a su domina-su dea- pues entre los tiernos poetas, confiesa, es el preferido de las lecturas de su amada:

Ardeo, mi Galeaz, mollem reperire Catullum, ut possim dominae moriger esse meae.

Lectitat illa libens teneros lasciva poetas, et praefert numeros, docte Catulle, tuos. (1-4)

La conjunción de estos aspectos que hemos expuesto, dibuja en conjunto una imagen novedosa de los personajes femeninos del Curial, que aglutinan diversos motivos de la tradición erótica grecorromana, sin que podamos percibir por parte del autor de la obra una actitud general de censura o un talante misógino por su parte, incluso en aspectos claramente condenables desde los parámetros morales de la época como el suicidio. ${ }^{52}$ Es un rasgo muy significativo de su reescritura personal de los motivos clásicos, revelador de una actitud antropocéntrica, de valoración, no ya en general del ser humano, sino más específicamente de la mujer, alejada del modelo dominante en la época medieval, que aprecia cualidades como su belleza, su gracia y refinamiento, su determinación en la relación amorosa, su habilidad para la música y el canto, incluso, como ejemplifica Càmar, su dimensión cultural como lectora de los clásicos.

1550 , sesenta y una mujeres como propietarias de libros -de ellas tan solo dos anteriores a 1400 y seis correspondientes a la primera mitad del siglo xV-, cuyo contenido manifiesta un interés específico, limitado en este período a obras de piedad en lengua vernácula: libros de horas, breviarios, libros de oraciones, salterios. Hasta 1479 no encontramos, en el inventario de la viuda de un notario mallorquín, obras de Cicerón, Séneca y Virgilio. Cf. Hillgarth, J. N. (1991): Readers and books in Majorca, París, CNRS, I, p. 44; p. 152).

51 CopPInI, Donatella, (1990): Antonii Panhormitae Hermaphroditus, Roma, Bulzoni.

${ }^{52}$ Es sumamente interesante contrastar esta actitud del autor del Curial, con la que muestran, por ejemplo, los escoliastas de algunos manuscritos españoles renacentistas de Propercio. Ma D. García de Paso Carrasco y G. Rodríguez Herrera han estudiado los marginalia de algunos códices y muestran cómo las glosas y marginalia presentan elementos que responden a una concepción extremadamente negativa de la mujer. Su estudio observa que los glosadores seleccionan e interpretan los textos de acuerdo con la visión cristiana misógina de la relación amorosa: «De esta manera recogen en sus comentarios aquellos tópicos y estereotipos elegiacos que inciden en los aspectos más negativos de la mujer — codicia, locuacidad, quejas, infidelidad...-, silenciando aquellos otros que nos ofrecen una perspectiva más favorable de la figura femenina como la puella diuina o la puella fidelis» (García de Paso, M.D., Rodríguez Herrera, G.[2005)]: «La consideración de la mujer en marginalia a las Elegías de Propercio», Faventia 27/1, p. 72). 